\title{
PROJETO ECO EMBAIXADOR AMBIENTAL práticas para a sustentabilidade
}

Carla dos Santos Rosário

Universidade do Vale do Itajaí (UNIVALI)

carlaspaz@hotmail.com

\begin{abstract}
Resumo
Os temas Meio Ambiente e Educação Ambiental são cobrados e enfatizados nas leis e documentos da educação de base para integrar padrões sustentáveis na vida humana. Diante da problemática dos resíduos plásticos poluidores do ambiente terrestre e aquático, juntamente com o comportamento não sustentável dos alunos da escola EEB XV de Junho, como sujar, depredar e o usar copos descartáveis, este trabalho objetivou a conscientização dos discentes a realizarem e participarem de situações relevantes para a prática da Educação Ambiental. O projeto durou seis meses e foi realizado nas turmas do $6^{\circ}$ ano I e $7^{\circ}$ ano II. O aluno representante "Eco Embaixador Ambiental" monitorava as ações insustentáveis da sala e fazia um relatório semanal para o professor. Também foram confeccionados 100 copos retornáveis resultando na redução de $11,55 \%$ no consumo dos copos descartáveis. Toda semana três alunos eram sorteados pelo representante da sala e apresentavam uma ideia de melhoria ambiental. Um ponto de coleta de óleo foi instalado na escola para a destinação adequada deste resíduo. Notou-se que a sensibilização foi parcial e temporária, existindo uma barreira entre o aprender na escola e aplicar em casa. O Eco copo foi bem aceito e utilizado, sendo recomendada a manutenção do uso de copos retornáveis, que são de fácil aquisição. O ponto de coleta óleo teve uma boa aceitação e auxiliou a compreensão da sua destinação. A necessidade de separação dos resíduos sólidos foi compreendida, mas muitos alunos tiveram dificuldade de aplicá-la com seus familiares. Conclui-se que é necessário a continuidade do trabalho para efetiva internalização dos conhecimentos e possibilitar a mudança dos conceitos equivocados e enraizados nas famílias e comunidade.
\end{abstract}

Palavras-chaves: Educação ambiental. Ensino de ciências. Meio ambiente. Sustentabilidade.

\section{ECO ENVIRONMENTAL AMBASSADOR PROJECT practices for sustainability}

\begin{abstract}
The themes Environment and Environmental Education are charged and emphasized in basic education laws and documents to integrate sustainable standards into human life. Given the problem of polluting plastic waste from the terrestrial and aquatic environment, together with the unsustainable behavior of EEB XV de Junho students, such as dirtying, preying and using disposable cups, this work aimed to raise the awareness of students to make and participate in situations relevant to the practice of Environmental Education. The Project lasted six months and was carried out in the 6th grade I and 7th grade II classes. The representative student "Eco Ambassador Ambiental" monitored the unsustainable actions of the class and made a weekly report to the teacher. 100 returnable cups were also made resulting in an $11.55 \%$ reduction in the consum of disposable cups. Each week three students were drawn by the class representative and made a weekly report for the teacher. 100 returnable cups were also made resulting in a reduction of $11.55 \%$ in the consumption of disposable cups. Every week, three students were drawn the room representative and presented an idea of environmental improvement. An oil collection point was installed at the school for proper disposal of this waste. It was noted that awareness was partial and temporary, with a barrier between learning at school and applying at home. The
\end{abstract}


Eco cup was well accepted and used, being recommended the maintenance of the use of returnable cups, which are easy to acquire. The oil collection point was well accepted and helped to understand its destination. The need for solid waste separation was understood, but many students had difficulty applying it with their families. It is concluded that the continuity of the work is necessary for the effective internalization of the knowledge and to make possible the change of the mistaken and rooted concepts in the families and community.

Keywords: Science teaching. Environmental education. Environment. Sustainability.

\title{
PROYECTO DE EMBAJADOR AMBIENTAL ECO prácticas para lasostenibilidad
}

\begin{abstract}
Resumen
Los temas del medio ambiente y la educación ambiental se encargan y se destacan en las leyes y documentos de la educación básica para integrar normas sostenibles en la vida humana. Ante el problema de los residuos plásticos que contaminan el medio ambiente terrestre y acuático, junto con los comportamientos insostenibles de los alumnos de la escuela EEB XV de Junho, como el ensuciamiento, la depredación y el uso de gafas desechables, esta obra tenía por objeto sensibilizar a los alumnos para que realizaran y participaran en situaciones relevantes para la práctica de la Educación Ambiental. El proyecto duró seis meses y se llevó a cabo en las clases de $6^{\circ}$ año I y $7^{\circ}$ año II. El representante de los estudiantes "Eco Embajador Ambiental" monitoreó las acciones insostenibles de la sala e hizo un reporte semanal al maestro. También se fabricaron 100 vasos retornables, lo que dio lugar a una reducción del 11,55\% en el consumo de vasos desechables. Cada semana tres estudiantes fueron sorteados por el representante del aula y presentaron una idea para la mejora del medio ambiente. Se instaló un punto de recogida de aceite en la escuela para la correcta eliminación de estos residuos. Se observó que la sensibilización era parcial y temporal, con una barrera entre el aprendizaje en la escuela y la aplicación en el hogar. La taza Eco fue bien aceptada y utilizada, siendo recomendado el mantenimiento del uso de tazas retornables, que son fáciles de adquirir. El punto de recogida de petróleo fue bien aceptado y ayudó a entender su destino. Se comprendió la necesidad de la separación de los desechos sólidos, pero muchos estudiantes tuvieron dificultades para aplicarla con sus familias. Se concluye que la continuidad del trabajo es necesaria para la efectiva internalización del conocimiento y para hacer posible el cambio de los conceptos equivocados y arraigados en las familias y la comunidade.

Palabras clave: Enseñanza de las ciencias. Educación ambiental. Medio ambiente. Sostenibilidad.
\end{abstract}




\section{INTRODUÇÃO}

As escolas são espaços onde os alunos exibem conceitos e ideias resultantes dos processos de construções empíricas repassadas pela educação de seus pais. Este espaço do saber e aprender formal, tem hoje uma das mais importantes concentrações de pessoas engajadas nos diversos tipos de conhecimentos não formal e informal da educação, como pais, alunos e até alguns funcionários. Considerando o que muitos autores argumentam como importante, o saber baseado na experiência do sujeito e a construção do indivíduo com o meio, deve ser levado em conta em todos os momentos do aprender pedagógico (VIGOTSKI, 1991; FREIRE, 1996; PIAGET, 2005). Cada docente deve fazer com que o processo de ligação deste conhecimento informal se encaixe com o aprender sistematizado apresentado pelas disciplinas oferecidas na educação de base (BRASIL, 1996).

A educação informal é o conhecimento prático e empírico, seguido da sabedoria comum e noções tradicionais. Não é uma educação constituída em disciplinas, e a aprendizagem é indutiva de reflexão e ação. Na educação não formal a aprendizagem dos indivíduos é fora do sistema escolar tradicional. Já na educação formal, existe valorização da educação possuindo ordem elevada e sistematizada do conhecimento (MARQUES; FREITAS, 2017).

Nas disciplinas de Ciências da Natureza e Biologia, os professores se tornam os responsáveis pelo processo de apresentação e informação sobre todos os conteúdos relacionados aos seres vivos, meio ambiente e bem-estar do corpo. Neste processo de aprendizagem, poucas disciplinas abordam a importância do cuidado com meio ambiente, apesar de vários documentos abordarem que este assunto é transversal (BRASIL, 1998; Brasil, 1999; BNCC, 2019), não precisando de uma única disciplina para sua aplicação e processo de desenvolvimento (BRASIL, 1999). Lamentavelmente, o tema meio ambiente vem sendo cada dia mais esquecido em todos os aspectos e procedimentos contextuais das demais disciplinas, as quais também deveriam abordar esse assunto no âmbito da Educação Ambiental. Esta falta de comunicação entre as demais disciplinas, escolas e órgãos públicos com a questão ambiental, vem contra as informações dos documentos citados e faz muitos professores e ambientalistas questionarem a necessidade de uma disciplina única para este tema.

A Educação Ambiental nos traz como embasamento a Política Nacional específica (Lei Federal $n^{\circ} 9.795 / 1999$ ), que diz que é direito de todos os cidadãos brasileiros o acesso 
aos conhecimentos, habilidades, valores sociais, atitudes e competências objetivando a qualidade de vida e a sustentabilidade do meio ambiente (BRASIL, 1999). No entanto, sabemos que esses valores, direitos e conhecimentos não são tratados de forma séria e na complexidade que deveriam ser abordados.

Os valores ambientais precisam estar presentes em todos os domínios educacionais e até mesmo nos órgãos públicos e nos campos familiares. Cada vez mais as pessoas estão vivendo por si só, sem imaginar de onde vêm seus objetos adquiridos (MMA, 2019). A facilidade de viver com toda comodidade, explorando nossos recursos naturais sem saber para onde vão e de onde vêm os objetos e bens de consumo é algo que conforta a consciência do ser humano. Por outro lado, o reconhecimento de que os recursos se esgotam, que os resíduos descartados incorretamente poluem e não se degradam rapidamente, já não é mais suficiente para quem tem conhecimento desta verdade.

Atualmente, é necessário trazer o problema da verdade inconveniente para nós, seres humanos, de forma mais impactante e direta, tornando-se claro que é preciso que a escola leve para o aluno a realidade do que ele vive e do que ele faz. O aluno poderá ser o vetor da transmissão destes valores para seus pais, familiares, comunidade e até mesmo para sua própria escola. Professores, escolas e os sistemas de educação devem fazer valer esses propósitos tão requeridos nos documentos e estudos vinculados à Educação Ambiental. A ausência de responsabilidade diante dos fatos vistos pela sociedade, tais como: o aumento da poluição, o desmatamento, a degradação de ambientes urbanos e florestais, a desvalorização do bem-estar, saúde e alimentação, faz com que soframos com a escassez de recursos, redução da qualidade de vida, danos à flora e fauna e contaminação dos ambientes naturais, tornando ineficazes os documentos e estudos já desenvolvidos. Segundo Freire (1987), a aquisição de caráter ocorre no momento em que a consciência ganha a dimensão da transcendentalidade, ou seja, ir além do que se sabe e identificar a realidade. Neste momento, o sujeito é libertado do meio em que estava envolvido, deixando-o, e encarando a realidade com consciência do mundo.

É preciso acreditar nas qualidades humanas voltadas para a busca do bem maior e de um mundo melhor, sem fragmentações na educação, na família, na comunidade, no trabalho e no planeta como um todo. Claramente, ninguém quer viver em um mundo poluído e degradado, tornando-se imprescindível o uso em nosso favor das premissas da Política da Educação Ambiental e de todos os documentos que nos amparam nesta educação dita transdisciplinar. Devemos entender que ao aprender sobre como proteger o meio ambiente 
em sua totalidade, respeitando o próximo, cuidando dos espaços em que convivemos, respeitando a comunidade, evitando a depredação dos bens públicos/privados, poluição, degradação e a indiferença com esses temas, forma-se um ser humano com consciência e responsabilidade social e ambiental, focado e empático para com a vida plena. Quando a criança aprende valores ambientais, vendo todos os aspectos que conectam sua vida com o mundo, ela se torna um ser humano de valor moral elevado (MMA, 2019).

Toda escola têm uma grande responsabilidade diante das ações de sustentabilidade, mas muito pouco tem sido feito para que de fato se resolvam os problemas relacionados à Educação Ambiental como um todo. Diante disso, o uso diário e frequente de copos descartáveis na Escola de Educação Básica XV de Junho de Itajaí-SC (EEB XV de Junho), a prática de jogar o lixo no chão das salas de aulas e as depredações feitas pelos próprios alunos, foram fatores que fortaleceram a ideia de que é preciso conscientizar os alunos a participarem de situações relevantes para a prática da Educação Ambiental.

O uso de copos descartáveis pela EEB XV de Junho é inverso aos parâmetros sustentáveis redigidos pelos documentos e estudos apresentados pela educação de base (PNC, 1998; BNCC, 2019). Existe uma grande necessidade de mudar comportamentos não sustentáveis e contrários às ações já reconhecidas. Portanto, é necessário compartilhar e ampliar a conscientização quanto à necessidade da diminuição do uso de plásticos descartáveis, do hábito de poluir o ambiente e da destruição de patrimônios, eliminando comportamentos autodestrutivos que impactam o ambiente interno ou externo e que causam danos a todos nós.

Por meio desta problemática insustentável objetivou-se conscientizar os alunos sobre a importância de cuidar do meio ambiente (natural e artificial) ${ }^{1}$ em que estão vivendo, sem depredar e sujar o espaço escolar e diminuir o uso de objetos poluidores, compartilhando ações sustentáveis na escola buscando então, especificamente:

- Sensibilizar os alunos a não jogarem lixo no chão da sala de aula e não depredar a escola;

- $\quad$ Evitar o uso dos copos descartáveis atualmente utilizados pela escola;

- Utilizar copos retornáveis elaborados pelo projeto;

- Realizar um ponto de coleta de óleo na escola;

\footnotetext{
${ }^{1} \mathrm{O}$ meio ambiente natural, está relacionado a biosfera e seus recursos naturais e o meio ambiente artificial é todo espaço construído, como edifícios comunitários, construções urbanas (SIRVINSKAS, 2015).
} 
- Incentivar os alunos a fazer a separação dos resíduos recicláveis em suas casas.

\section{MATERIAIS E MÉTODOS}

A EEB XV de Junho localiza-se na Avenida Ministro Luiz Gallotti, Bairro Cidade Nova, Itajaí/SC. A Escola possui 14 salas de aula, 1 biblioteca, 1 sala do diretor, 1 secretaria, 1 sala dos professores, 1 sala do SAED, 1 cozinha, 4 banheiros dos professores ( 2 masculinos e 2 femininos), 8 banheiros para os alunos (4 masculinos e 4 femininos), 1 quadra sem cobertura, 1 espaço livre (horta) e 1 estacionamento para os funcionários. Conta com 5 funcionários na limpeza, 2 na cozinha, 1 vigilante, 60 professores, 2 assessoras, 1 supervisora, 1 secretária, 2 estagiárias e 880 alunos matriculados.

Este trabalho foi realizado no período vespertino (das $13 \mathrm{~h} 30$ às $17 \mathrm{~h} 30$ horas) somente com alunos de 12 a 13 anos das turmas do $6^{\circ}$ ano I e $7^{\circ}$ ano II, com início no mês de maio 2019 e término no final do mês de novembro deste mesmo ano. O trabalho foi proposto inicialmente para a turma do $7^{\circ}$ ano II, em virtude de a professora da disciplina Ciências da Natureza também ser a professora regente, a qual é responsável por propor e orientar trabalhos e projetos com os alunos. Posteriormente, a turma do $6^{\circ}$ ano I solicitou a participação no projeto, após conhecê-lo. As demais turmas $\left(6^{\circ}\right.$ a $9^{\circ}$ anos) foram convidadas para participar, porém somente manifestaram interesse na compra dos Eco copos e na entrega de óleo utilizado.

Os docentes do ensino fundamental e médio foram comunicados sobre a execução do projeto, mas apenas poucos participaram de forma indireta através da compra dos Eco copos reutilizáveis. Não houve ampliação da execução do projeto externamente à escola, sendo esperado que os alunos pudessem levar o aprendizado para as suas famílias e, consequentemente, para a comunidade. Tratava-se de uma comunidade que pouco participava do ambiente escolar que raramente participava de reuniões e encontros.

A metodologia utilizada para o desenvolvimento do senso de respeito ao meio ambiente natural e artificial foi iniciada com uma definição das atitudes sustentáveis e insustentáveis que poderiam ser praticadas no âmbito escolar. Definiram-se atitudes sustentáveis como sendo as práticas de redução de geração de lixo, uso de copos reutilizáveis, respeito e zelo com o espaço das salas de aulas/escola e busca de ideias ambientalmente corretas para a discussão entre a turma. Essas atitudes estão inseridas nos objetivos de desenvolvimento sustentável definidos pela Organização das Nações Unidas - 
ONU (2015), porém apenas vinculados às dimensões social e ambiental. O conceito de sustentabilidade possui muitas vertentes, dentre elas a ambiental e a social (MMA, 2004).

Já as atitudes não sustentáveis vinculavam-se principalmente no desrespeito ao ambiente escolar. Posteriormente, a turma elegeu um presidente de sala e um representante (nomeado Eco Embaixador Ambiental). O representante ajudava o presidente nas ações que deveriam ser desempenhadas pelos estudantes da sala de aula, em conformidade com a definição de sustentabilidade proposta. As más ações realizadas pelos alunos foram anotadas pelo presidente e o Eco Embaixador e, no final de cada semana (sexta-feira), ambos entregam para professora orientadora um relatório da sala com os seguintes comportamentos:

- Lixos jogados no chão da sala;

- Carteiras riscadas;

- Depredação do espaço.

Os alunos que desrespeitavam a regras de sustentabilidade tiveram pontos perdidos e estes pontos foram descontados na nota. As boas ações fizeram com que o aluno ganhasse pontos, desde que enquadradas nas ações abaixo:

- Trazer toda sexta-feira uma ideia de melhoramento ambiental e apresentar para turma;

- Ajuda na elaboração do copo retornável (desenho vetor) do projeto;

- Divulgação da venda dos Eco copos na escola toda;

- Utilização dos copos retornáveis, mesmo que não fosse o copo do projeto;

- Evitar o uso dos descartáveis da escola.

No final do último trimestre do ano letivo, dois pontos de comportamento sustentável foram dados ou retirados dependendo das atitudes de cada aluno.

Após a implantação o projeto em sala de aula, iniciou-se a venda dos Eco copos retornáveis, com um custo de $\mathrm{R} \$ 3,21$ por unidade. $\mathrm{O}$ copo foi cotado e produzido pela empresa Meu Copo Eco de Florianópolis. O custo de frete e negociação foi realizado pela professora orientadora e o valor total da compra de 100 unidades dos Eco copos foi de $\mathrm{R} \$$ 321,00. A turma da sala do $7^{\circ}$ ano II escolheu o tema para personalizar o copo do projeto, desenhando um golfinho feliz no mar (Figura 1) que representou a importância de preservação dos mares, a necessidade da diminuição do uso de plásticos e o descarte indevido do óleo de cozinha que polui o ambiente natural (terrestre e aquático). 
Não houve nenhuma arrecadação financeira para o professor ou para a escola, constando na nota fiscal o valor declarado (preço unitário e valor total da compra).

Figura 1. Desenho realizado pelos alunos da turma $7^{\circ}$ ano II - EEB XV de JUNHO - ITAJAÍ/SC, 2019.

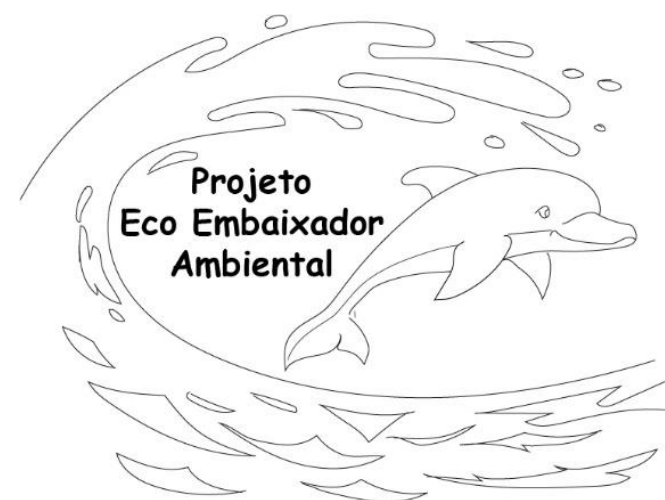

Fonte: A autora (2019)

O copo resultante do projeto (Figura 2) foi apresentado na Feira de Ciências para que fosse evidenciada a importância de usar menos os descartáveis e mais os retornáveis, demonstrando assim, que é possível adquirir materiais sustentáveis que melhorem de forma construtiva, o ambiente escolar.

Figura 2. Copo do Projeto Eco Embaixador Ambiental finalizado - EEB XV de JUNHO ITAJAÍ/SC, 2019.

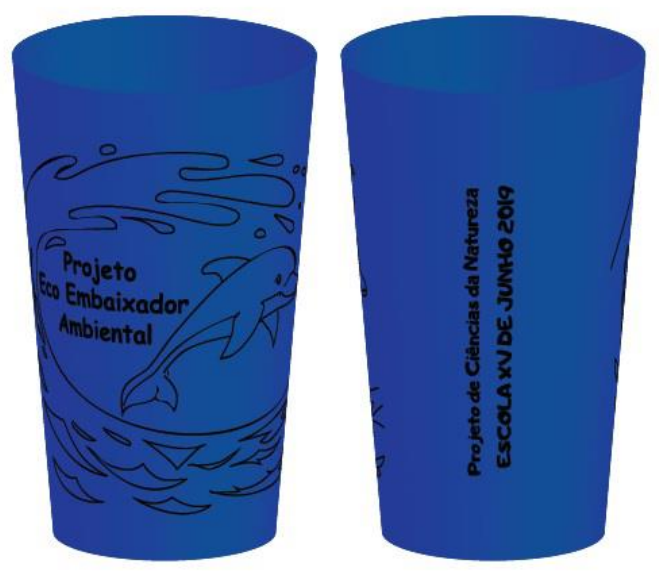

Fonte: A autora (2019)

Este projeto foi para a Feira de Ciências, sendo necessária a inclusão da discussão sobre o uso indiscriminado de plásticos e óleos. Dessa forma, foram confeccionados e apresentados modelos de células procariontes para representar as seguintes bactérias: 
Alcanivorax borkumensis, bactéria degradadora do óleo e que se alimenta de hidrocarbonetos; e a Ideonella sakaiensis bactéria degradadora de plástico que produz a enzima PETase que ataca e decompõe polímeros plásticos em pequenas unidades. Essa complementação possibilitou a ampliação do conhecimento sobre a importância dos seres microscópicos como aliados do meio ambiente e não apenas como vilões ou causadores de doenças e epidemias, fato que também permitiu a correlação entre Educação Ambiental e Ciências da Natureza. Ainda no âmbito da Feira de Ciências foi demonstrado o consumo de óleo semanal por cada família dos alunos, possibilitando a visualização e quantificação do problema. As ações permitiram o entendimento sobre a necessidade de diminuição da geração do resíduo sólido (copos descartáveis), líquido (óleo usado) e o descarte devidamente correto, bem como no reconhecimento da importância das bactérias como aliadas nas ações sustentáveis.

Para confecção das bactérias foram utilizados prioritariamente materiais reciclados entre outros:

- Garrafas pets;

- Cola quente;

- Tinta guache, pincel, barbante, tesoura e papel.

Para a elaboração dos modelos, priorizou-se o uso de materiais recicláveis trazidos pelos próprios alunos e aqueles disponíveis de outros trabalhos (da educação infantil) que seriam descartados pela escola, permitindo a visualização e valorização de resíduos que fatalmente seriam dispostos de forma inadequada no lixo comum ou seriam subaproveitados. $\mathrm{O}$ uso de isopores ou outros materiais facilmente adquiridos no comércio seria totalmente contrário aos objetivos gerais do trabalho. As bactérias citadas como modelo de células procariontes, foram elaboradas por dois alunos do $7^{\circ}$ ano II, que representaram a escola na Feira Regional de Ciências e Tecnologia de Itajaí-SC em 2019.

\section{RESULTADOS E DISCUSSÕES}

Durante a aplicação das ações do Projeto Eco Embaixador ambiental, os alunos sentiram-se envergonhados quando foram citados nos relatórios elaborados no final de cada semana, sendo os responsáveis pelo lixo jogado no chão e/ou depredações. Os relatórios, 
feitos pelo presidente e pelo representante Eco Embaixador Ambiental de sala, descreviam as atitudes dos alunos que não estavam no contexto e premissas do projeto. Após a citação nos relatórios, os alunos registrados reconheciam que estavam errados em praticar as ações insustentáveis, tentavam mudar e paravam de fazê-las por um tempo. Porém, sempre que ocorriam feriados, paradas da escola para reuniões, férias, festas ou jogos, acabavam voltando mais indisciplinados. Acredita-se que a ausência de cobranças, incentivos e exemplos no ambiente domiciliar ou extraescolar, possam explicar tais alterações.

Para Jacobi (2003), o maior desafio para os educadores ambientais é resgatar desenvolvimento de valores e comportamentos, como o respeito, compromisso, responsabilidade e confiança. Já Mendes (2009), cita que o ser humano possui princípios enraizados pela sociedade e que a suposta mudança evolutiva é superficial, pois existe uma busca desenfreada do ter e não do ser. Segundo Freire (1987), a aquisição de caráter ocorre no momento em que a consciência ganha dimensão da transcendentalidade, ou seja, ir além do que se sabe e identificar a realidade. Neste momento, o sujeito é libertado do meio em que estava envolvido, deixando-o, e encarando a realidade com consciência do mundo.

Foi necessário um grande esforço da professora orientadora, pois mesmo relembrando que os discentes eram responsáveis pelo bom andamento do projeto e que precisavam dar exemplos para as demais turmas, além de estarem sujeitos as regras de pontuação, eles possuíam grande dificuldade de melhorar e manter o comportamento. A indisciplina deixou bem claro o quanto os pais eram responsáveis pelo comportamento da educação informal reproduzida por eles. No estudo de Trilla (1993), é descrito que a educação informal é um processo educativo indiferenciado onde a função de educar não é dominante e não tem especificidade, como por exemplo, a educação dada pelos pais. E a educação formal é processo sistemático de escolarização onde a criança aprende sobre todas as disciplinas e temas transversais. Já a educação não formal é obtida por cursos, palestras, seminários, debates, rodas de conversas e estes conhecimentos são obtidos fora do ambiente escolar.

Percebeu-se que fatores emocionais relacionados ao convívio familiar como violência doméstica, abuso sexual, abandono dos pais, separações conjugais, desinteresse dos pais sobre a vida escolar dos filhos dificultaram bastante o caminhar educativo proposto, desviando-os do tema central da educação ambiental e sustentabilidade, tornando-se um grande entrave na aquisição de novos valores. O aluno com sentimentos negativos, vinculados aos problemas acima, tem dificuldade de internalizar a importância do tema. É 
como se construísse em sala de aula e desconstruísse em casa, consecutivamente. Para Rosário (2019), as crianças aprendem e questionam os seus cuidadores nas ações negativas, mas quando seus responsáveis não estão dedicados a ouvir e aprender, a criança passa a reproduzir o que é oferecido para ela, tornando a educação lenta e difícil. Problemas gerados na escola, tais como bullying, racismo e violência física também afetavam negativamente, mas eram trabalhados entre o docente e os alunos envolvidos através de teatros, debates, depoimentos e palestras.

Quanto aos Eco copos, foi preciso atingir o pedido mínimo de 100 unidades, através da compra pelos alunos e professores, para que a encomenda/fabricação pudesse ser realizada. Com a participação das representantes do projeto da turma $6^{\circ}$ ano I e da turma do $7^{\circ}$ ano II, o valor para a compra dos Eco copos foi sendo arrecadado e os nomes dos compradores anotados. Quando a venda na escola foi encerrada, o pedido de fabricação e compra foi feito junto à empresa e, posteriormente, todos os alunos e professores que participaram receberam o copo personalizado do projeto (Figura 3, 4 e 5). Nem todos os alunos e professores quiseram adquirir copo e por isso apenas 100 unidades foram vendidas. Destaca-se que a escola possui muitos alunos carentes e que a ausência de uma maior adesão à compra pode estar relacionada a esse fator.

É importante destacar que a escola teria a responsabilidade de incentivar o hábito da sustentabilidade e compreender os projetos de seus docentes, podendo incentivar o uso dos copos reutilizáveis. Um trabalho só pode ser valorizado e ter mudanças significativas com o apoio de toda gestão escolar. Os copos descartáveis eram oferecidos somente durante a merenda (suco), os quais acabavam sendo descartados em lixeiras comuns sem qualquer tipo de segregação, apesar da escola possuir recipientes de separação dos resíduos. O colégio dispunha de torneiras para as crianças beberem água e os copos descartáveis não eram distribuídos para este fim. Poucos alunos levavam garrafinhas para armazenar água durante o período de aula, mas muitos alegavam que esqueciam ou não as tinham.

Segundos os dados obtidos pela secretaria da escola, em um só dia são usados aproximadamente 472 copos descartáveis. Utilizando-se estes dados para estimar o uso de copos por mês, resultaria em 10.384 copos/mês (472 copos x 22 dias úteis). Como a escola possui 880 alunos, pode-se calcular o consumo médio de copos por aluno (10.384/880) resultando em 12 copos aluno/mês. Com o uso de 100 copos do projeto, ou seja, 100 alunos que deixam de utilizar copos descartáveis, estima-se uma redução de 1.200 copos/mês (100 
alunos x 12 copos) que deixam de ser utilizados na escola, equivalente a uma redução de $11,55 \%$.

Os Eco copos reutilizáveis eram utilizados tanto para o momento da merenda (suco), quanto para a coleta de água das torneiras, sendo de responsabilidade de cada aluno os cuidados de higienização. A escola não disponibilizava detergente e/ou sabão para a limpeza dos Eco copos, os quais eram lavados apenas com água pelo próprio aluno. Alguns poucos alunos levavam toalhinhas para secar o Eco copo após o uso. Quando algum aluno esquecia o Eco copo reutilizável, acabava utilizando o copo descartável, porém se demonstrava chateado por estar gerando resíduo plástico desnecessariamente.

Figura 3. Aluna do fundamental I que adquiriu o copo e usa diariamente - EEB XV de JUNHO - ITAJAÍ/SC, 2019.

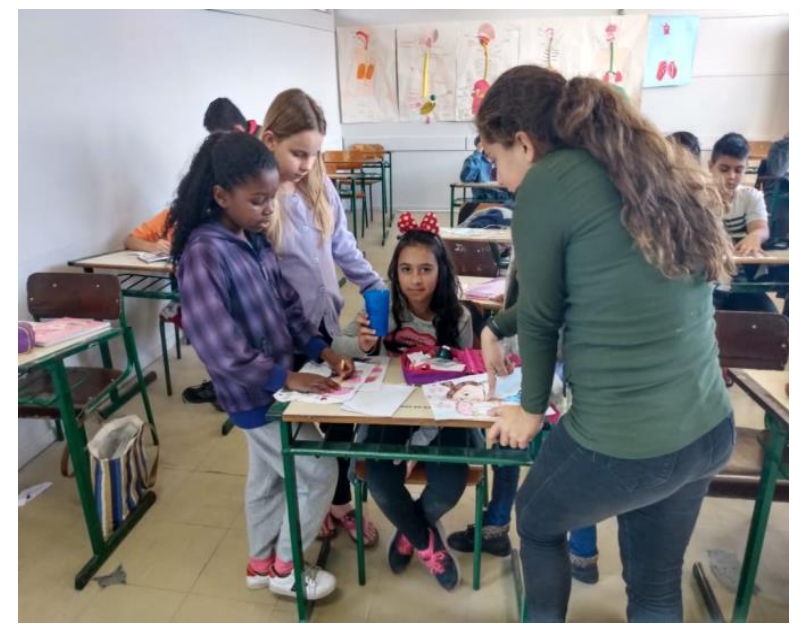

Fonte: A autora (2019).

Figura 4. Alunos do fundamental I que adquiriram o copo e utilizam a escola - EEB XV de JUNHO - ITAJAÍ/SC, 2019.

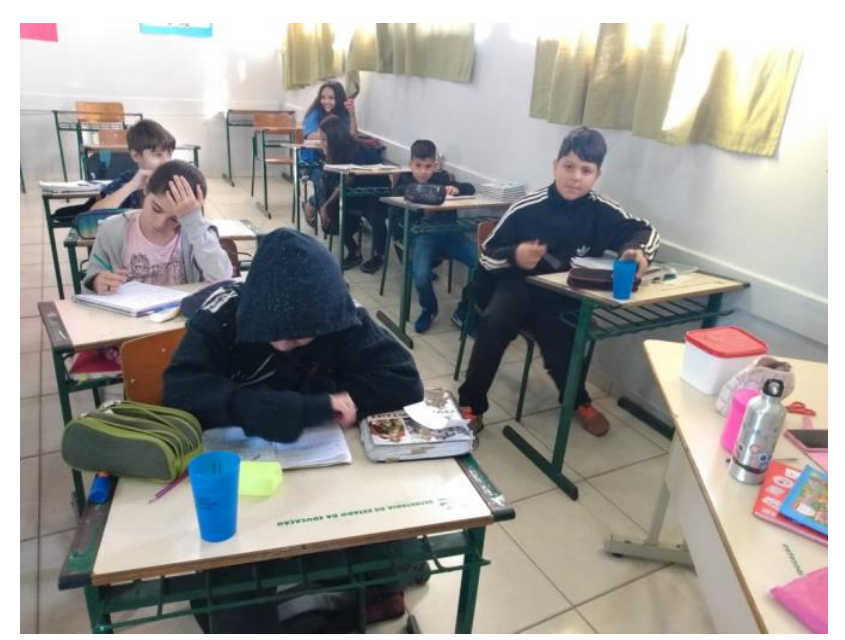

Fonte: A autora (2019). 
Figura 5. Alunos do fundamental II e a professora com seus Eco copos - EEB XV de JUNHO ITAJAÍ/SC, 2019.

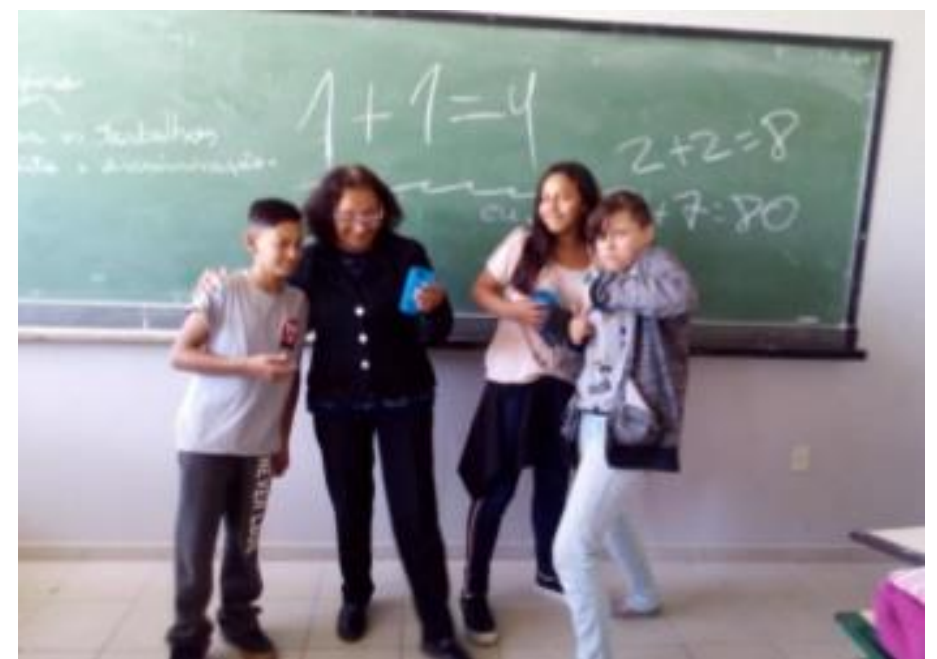

Fonte: A autora (2019).

O projeto alcançou o objetivo de implantação de um ponto de coleta de óleo (bombona plástica de 50 1), que foi instalado no início do mês de setembro de 2019, nas dependências da escola (EEB XV de Junho) em local coberto e isolado. Ele foi solicitado junto ao órgão ambiental do município de Itajaí (Instituto Cidade Sustentável de Itajaí), o qual indicou a empresa Itá Resíduos Coleta de Óleos de Cozinha Usado. No momento em que a bombona estivesse cheia a empresa realizaria a coleta e destinaria o óleo para fabricação de biodiesel e ração. Os alunos foram informados sobre a destinação final do óleo coletado, sendo trabalhado o conceito de reciclagem e geração de renda com esse resíduo.

Também trouxeram certa quantidade de óleo que foi usado durante a semana em suas casas, demonstrando assim, a quantidade de resíduos gerada e a preocupação quanto à possibilidade de poluição do meio ambiente, caso o óleo usado não tivesse sido corretamente destinado (Figura 6). Alguns alunos descreveram que seus vizinhos fabricavam sabão e que suas mães destinavam o óleo usado para esse fim, objetivando a troca ou compra, por um preço reduzido, do sabão produzido. Outros alunos descreveram que nas suas casas o óleo era jogado na pia da cozinha e que não sabiam o que poderia acontecer para o meio ambiente. As diferentes destinações do óleo utilizado foram discutidas e possibilitou aos alunos a constatação dos benefícios que podem ser gerados com aquele resíduo, bem como os severos malefícios que causam ao meio ambiente quando são descartados de forma inapropriada, como por exemplo, a contaminação de mananciais e oceanos e entupimento das redes de esgoto. Tais ações vêm de encontro à citação de Santos \& Gardolinsk (2013) que indicam 
que a escola contribui para que o aluno adquira hábitos que sejam vivenciados também na família e na comunidade. 
Figura 6. Aluno do $7^{\circ}$ ano II apresentando o óleo coletado em casa durante o período de uma semana - EEB XV DE JUNHO - ITAJAÍ/SC, 2019.

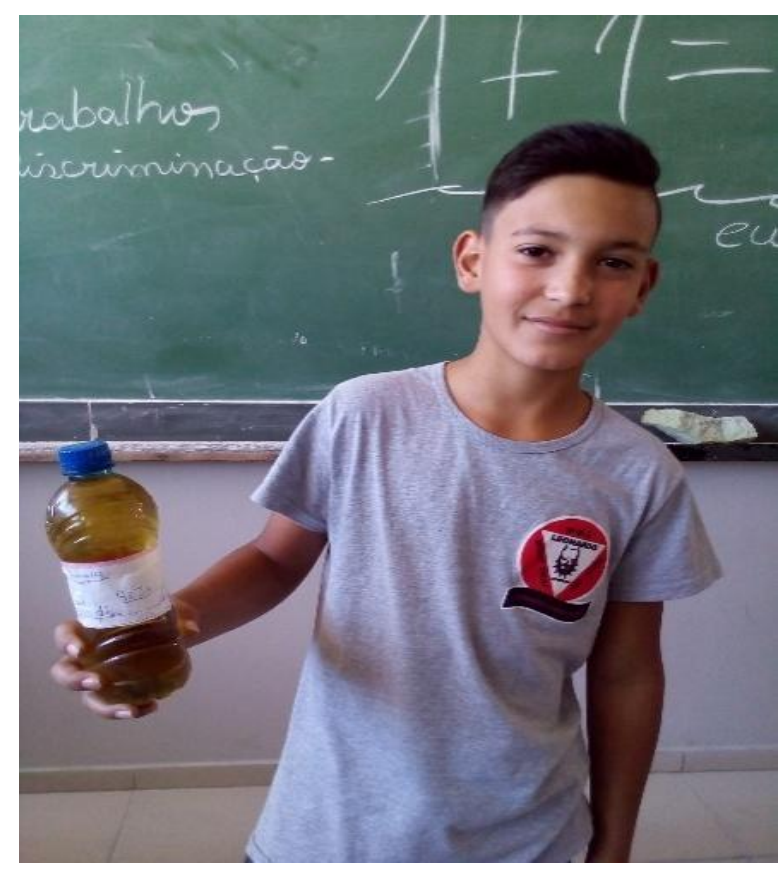

Fonte: a autora (2019).

Durante a execução do projeto, alguns dos alunos que foram sorteados a cada semana, trouxeram ideias sustentáveis de melhoria do meio ambiente. Apresentaram em sala de aula exemplos de resíduos sólidos ${ }^{2}$ gerados em suas casas e que podiam ser reciclados e separados dos rejeitos ${ }^{3}$. Esse fato ganhou importância na medida em que existem muitos coletores de resíduos que residem no bairro, sendo alguns deles pais dos alunos que frequentam a escola. Os resíduos sólidos utilizados nas demonstrações em aula, após o uso, foram adequadamente destinados pela professora orientadora do projeto. Já o reconhecimento de que há outros materiais como o óleo de cozinha que podem ser reciclados e, como consequência gerar renda, ampliou a noção de sustentabilidade dos alunos.

Muitos alunos relataram que seus pais achavam que era irrelevante o que a professora havia ensinado e que não seria preciso tantas mudanças para se viver. Alguns pais disseram que bastaria que a escola lhes ensinasse a escrever e ler. Outro grupo de alunos informou que seus pais acharam muito difícil fazer o correto descarte dos resíduos sólidos, separando-

\footnotetext{
${ }^{2}$ Resíduos sólidos: é tudo que tem valor econômico e pode ser reciclado ou reaproveitado (BRASIL, 2010).

${ }^{3}$ Rejeitos: é tudo que não pode ser reciclado ou reutilizado, sendo assim, classificados como lixo (BRASIL, 2010).
} 
os dos rejeitos, justificando que, mesmo que realizassem a separação, nunca viram a coleta seletiva passar na rua em que moravam. Justificaram que não precisaria separar os diferentes resíduos, uma vez que o caminhão do lixo comum coleta tudo, misturando-os novamente. Tais problemas demonstraram que, de fato, não existia estímulo na separação dos resíduos, uma vez que a comunidade se sentia desvalorizada em fazer algo ineficaz, decidindo então, por não fazê-lo.

Durante as apresentações das propostas de melhoria ambiental, foi sugerido aos alunos que fossem realizadas queixas junto à prefeitura municipal, para que o caminhão de coleta seletiva pudesse passar com maior frequência em todas as ruas do bairro. Essa proposta trouxe a percepção aos alunos que todos possuem o direito a um meio ambiente urbano equilibrado e que podemos participar e podemos cobrar os responsáveis na busca da sustentabilidade.

Mesmo com tanta dificuldade para trabalhar a Educação Ambiental, é extremamente importante a valorização daqueles que conseguem compreender e se adaptar a tantas formas diferentes de conviver com a vida sustentável. Sabe-se que não é fácil mudar hábitos enraizados e repassados através da educação informal, pois não existem valores ambientais para quem não os conhecem. Ainda assim, percebeu-se que um número pequeno de alunos conseguiu aplicar as práticas sustentáveis em suas casas, tornando-se efetiva a mudança naqueles que se dispuseram à mudança.

Apesar dos diferentes problemas envolvidos na condução do trabalho, percebeu-se que muitos alunos sentiam-se carentes de atenção e queriam assumir algum tipo de responsabilidade. Mesmo aqueles que não foram responsáveis diretos participaram do projeto através de conversas e desabafos, levando à escola os problemas que carregam consigo. Freire (1996) ressalta que somos seres inacabados, portanto, sempre em processo de construção e reconstrução.

As ações realizadas no âmbito do projeto Eco Embaixador Ambiental, juntamente com os modelos de bactérias procarióticas degradadoras de resíduos plásticos e óleos (Figura 7 e 8), foram apresentados na Feira Regional de Ciências e Tecnologia de Itajaí-SC, onde dois alunos sorteados (número máximo de participantes) do $7^{\circ}$ ano II, foram os representantes da escola obtendo o $5^{\circ}$ lugar na classificação geral (Figura 9 e 10). 
Figura 7. Célula procariótica, bactéria (Ideonella sakaiensis) confeccionada pelo aluno da EEB XV DE JUNHO - Itajaí-SC, 2019.

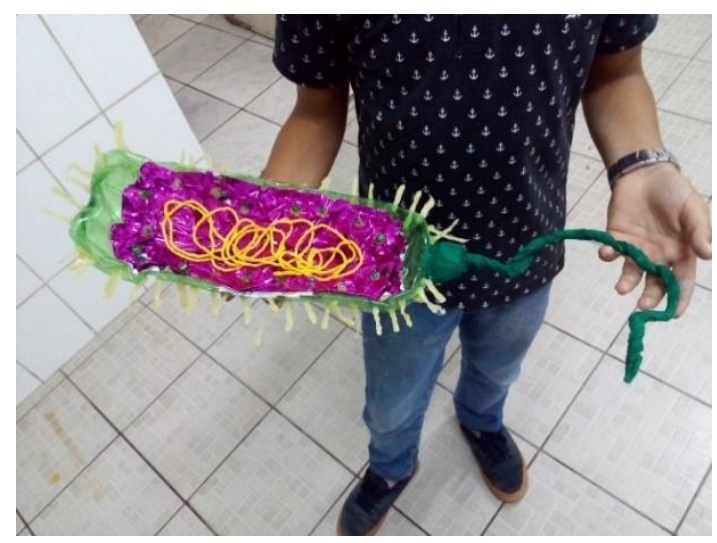

Fonte a Autora (2019).
Figura 8. Célula procariótica, bactéria (Alcanivorax borkumensis) confeccionada pelo aluno da EEB XV DE JUNHO - ItajaíSC, 2019.

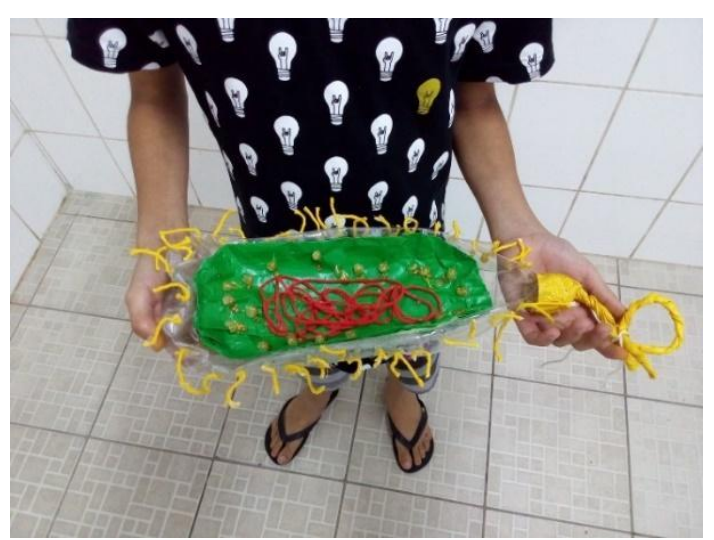

Fonte a Autora (2019).

Figura 9. Alunos representantes do Projeto na XII Feira de Ciências e Tecnologia, 2019.

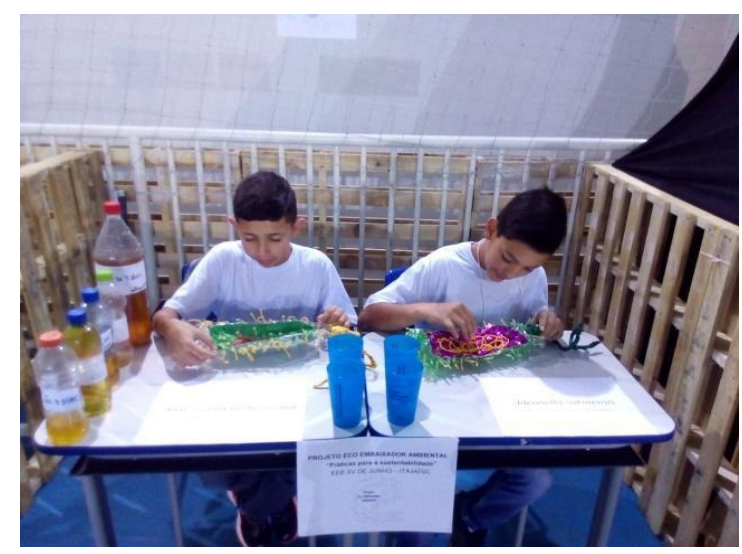

Fonte: A autora (2019). 
Figura 10. Classificados em $5^{\circ}$ lugar na XII Feira Regional de Ciências e Tecnologia - ItajaíSC, 2019.

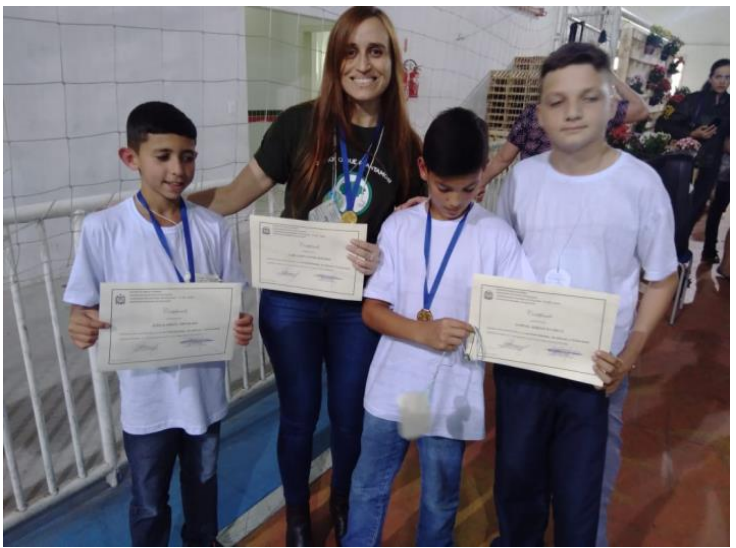

Fonte: A autora (2019).

\section{CONCLUSÃO}

As práticas de educação ambiental voltadas para a sensibilização e despertamento da necessidade de respeito ao meio ambiente natural e artificial foi parcialmente atingida, uma vez que as ações de zelo com o ambiente escolar não atingiram a todos e foram temporários, não se mantendo mesmo após breves períodos de distanciamento da escola. Foi possível notar mudanças em alguns alunos, mas para a maior parte tornou-se claramente visível a existência de uma grande barreira entre o aprender na escola e aplicar as práticas, dia a dia, em suas casas.

Os Ecos copos tiveram uma boa aceitação e uso pelos alunos do projeto e reduziu em 11,55\% a utilização dos copos descartáveis. Percebeu-se que sem o total envolvimento dos professores e da direção escolar a adoção do uso de Eco copos torna-se uma medida isolada e dificultosa. Recomenda-se que a obtenção e disponibilização de copos reutilizáveis possa ser uma política incentivada pelos diretores ou até mesmo adotada pelo estado, pois os copos retornáveis são de fácil implementação e baixo valor aquisitivo seja por projetos, gestão escolar ou ação governamental.

A instalação do ponto de coleta de óleo disponibilizou a comunidade uma opção para o correto descarte, reduzindo o impacto negativo daqueles que ainda descartavam o óleo nas pias. Também houve a conscientização entre os alunos sobre demais formas de reciclagem 
e possível geração de troca ou renda com esse resíduo, como, por exemplo, na fabricação caseira de sabão.

A discussão sobre o incentivo à separação de resíduos recicláveis proporcionou o conhecimento acerca da problemática, o senso crítico entre os alunos e a busca para a solução da ausência de coletas regulares em todas as ruas do bairro. Poucos alunos conseguiram levar os conhecimentos adquiridos para provocar mudanças nos hábitos de seus familiares.

Conclui-se que o Projeto Eco Embaixador Ambiental, assim como os demais projetos de Educação Ambiental, deve ser realizado de forma continuada, a fim de vencer, gradualmente, os conceitos equivocados enraizados nas famílias e comunidade que não tiveram acesso ao conhecimento, proporcionando aos alunos a internalização do tema através do reconhecimento dos direitos e deveres para a busca de um meio ambiente sustentável. Sendo assim, recomenda-se a continuidade deste trabalho pelos próximos docentes. 


\section{REFERÊNCIAS}

BRASIL. Lei no 9.394, de 20 de dezembro de 1996. Lei de Diretrizes e Bases da Educação Nacional ( $L D B)$. Disponível em: www.planalto.gov.br. Acesso em: 11 ago. 2019.

BRASIL. Secretaria de Educação Fundamental. Parâmetros curriculares nacionais (PCN): terceiro e quarto ciclos do ensino fundamental: Introdução aos parâmetros curriculares nacionais - Secretaria de Educação Fundamental. - Brasília: MEC/SEF, 1998. $174 \mathrm{p}$.

BRASIL. Lei no 9795, de 27 de abril de 1999. Dispõe sobre a educação ambiental, institui a Política Nacional de Educação Ambiental e dá outras providências. Brasília: MEC, 1999.

BRASIL. Lei $\mathbf{N}^{\circ} 12.305$ de 02 de agosto de 2010. Política Nacional de Resíduos Sólidos (PNRS).

BRASIL. BNCC. Ministério de Educação. Base Nacional Comum Curricular: Educação é a Base, $2019 . \quad$ Disponível em: http://basenacionalcomum.mec.gov.br/images/BNCC_EI_EF_110518_versaofinal_site.pd. 2019.

BRASIL. Ministério de Educação. Temas Contemporâneos Transversais na BNCC: contexto histórico e pressupostos pedagógicos. Brasília: MEC, 2019. Disponível em: http://basenacionalcomum.mec.gov.br/images/implementacao/contextualizacao_temas_con temporaneos.pdf. Acesso em: 11 de agosto de 2019.

BRASIL. Ministério do Meio Ambiente (MMA). Crianças e o consumo sustentável. 2019.

BRASIL. Ministério do Meio Ambiente (MMA). O que é consumo sustentável. Disponível em: $\quad$ https://www.mma.gov.br/responsabilidade-socioambiental/producao-e-consumosustentavel/conceitos/consumo-sustentavel. Acesso em: 11 de agosto de 2019.

FREIRE, P. Pedagogia da autonomia: saberes necessários a prática educativa. 23. ed. São Paulo: Paz e Terra, 1996.

FREIRE, P. Pedagogia do oprimido. 17. ed. Rio de Janeiro: Paz e Terra, 1987.

JACOBI, P. Educação ambiental cidadania e sustentabilidade. Caderno de Pesquisa, [s.1], n. 118, p. 189-205,2003.

MARQUES, J. B. V; FREITAS, D. Fatores de caracterização da educação não formal: uma revisão da literatura. Pesquisa, São Paulo, v. 43, n. 4, p. 1087-1110, 2017.

MENDES, J. M. G. Dimensões da sustentabilidade. Revista das Faculdades Santa Cruz, [s.1], v.7, n.2, p. 49-59.

MINISTÉRIO DO MEIO AMBIENTE (MMA); Brasil. Caderno de Debate: agenda 21 e sustentabilidade: um novo modelo de sustentabilidade. Brasília: 2004. 12 p. Disponível em: 
https://www.mma.gov.br/estruturas/agenda21/_arquivos/caderno_rosa.pdf. Acesso em: 12 junho 2020.

NACIONAL INFANTO-JUVENIL PELO MEIO AMBIENTE, 4., 2013, Brasília. Disponível em: http://file:///C:/Users/Carla/Downloads/Susana\%20Peres\%20dos\%20Santos.pdf. Acesso em: 12 de agosto de 2019.

ONU (Brasil). Nações Unidas Brasil (org.). Objetivos de Desenvolvimento Sustentável: Transformando Nosso Mundo: a agenda 2030 para o Desenvolvimento Sustentável, 2015. Disponível em: https://nacoesunidas.org/pos2015/agenda2030/. Acesso em: 13 outubro 2015.

PIAGET, L. A linguagem e o pensamento da criança. 7. ed. São Paulo: Martins Fontes, 2005.

ROSÁRIO, C. dos S. Educação Ambiental e atividades lúdicas para a identificação da importância das distintas formas de vida (fauna e flora). Revista Brasileira de Educação Ambiental (RevBEA), [s.1], v. 14, n. 3, p. 155-168, 2019.

SANTOS, S. P.; GARDOLINSKI, T. H. A. A importância da educação ambiental nas escolas para a construção de uma sociedade sustentável. In: CONFERÊNCIA

SIRVINSKAS, Luís Paulo. Manual de direito ambiental. 13 ed. São Paulo: Saraiva, 2015.

TRILLA, J. B. La educaciónfuera de laescuela:Ambitos no formales y educación social. Barcelona: Ariel, 1993,p. 23-27.

VYGOTSKY, L. A formação social da mente: O desenvolvimento dos processos psicológicos superiores. 4.ed. São Paulo: Martins Fontes, 1991. 